\section{Cellules stromales mésenchymateuses et cancer}

\section{Espoirs ou craintes?}

Florence Apparailly, Christian Jorgensen, Gwendal Lazennec
Inserm, U844, INM, Hôpital Saint Eloi,

80 rue Augustin Fliche,

34295 Montpellier Cedex 5, France.

Université Montpellier 1, UFR de Médecine,

34000 Montpellier, France.

CHU Lapeyronie, service d'Immuno-

Rhumatologie, 34000 Montpellier, France.

appara@montp.inserm.fr

tant une xénogreffe tumorale montrent dans la plupart des cas une capacité des CSM à migrer vers la tumeur [6]. Les CSM sont aussi capables dans certains cas de stimuler la croissance tumorale, sans doute via la production de facteurs proangiogéniques. Nous avons également mis en évidence un pouvoir immunosuppresseur des CSM sur les lymphocytes $B$ et $T$ qui conduit à une stimulation de la croissance tumorale [7]. Une des questions les plus controversées concerne le pouvoir inhibiteur ou stimulateur des CSM sur la croissance tumorale. Selon l'origine des CSM utilisées, le site de la tumeur et le type de cellules tumorales employées, les résultats varient de l'inhibition de la croissance tumorale à sa stimulation, en passant par une absence d'effet.

Les données les plus étonnantes sont celles qui sont rapportées récemment par le groupe de R. Weinberg qui montre que la co-implantation sous-cutanée de CSM humaines primaires et de cellules tumorales provenant de lignées de cancer du sein humain (MDA-MB-23l et MDA-MB-435) chez des souris immunodéficientes n'affecte pas la croissance tumorale, mais favorise le développement de métastases [8]. Cet effet pro-métastatique implique la sécrétion de la chimiokine CCL5 (Rantes) par les CSM, augmentant ainsi le pouvoir invasif des cellules cancéreuses. À l'inverse, d'autres équipes rapportent une inhibition de la croissance tumorale par les CSM via la répression de l'activité Akt des cellules tumorales [9]. Cependant, il est difficile de comparer ces deux études car les modes opératoires 
utilisés diffèrent en plusieurs points. Bien que les cellules cancéreuses soient implantées dans les deux études en sous-cutané chez des souris athymiques, leur nature est différente. Dans l'étude de Khakoo et al., citée ci-dessus [9], les cellules utilisées sont des cellules du sarcome de Kaposi qui sont issues de tumeurs de tissus mésenchymateux, et non de tissus épithéliaux. De plus, la voie d'administration des CSM humaines primaires est différente. Khakoo et al. les injectent par voie intraveineuse. II n'en reste pas moins que de telles expériences doivent être reproduites avec des souris possédant un système immunitaire intact afin d'intégrer l'ensemble des composantes mises en jeu dans les interactions entre la tumeur et les CSM. Ce dialogue entre ces deux types de cellules est d'autant plus complexe que les cellules cancéreuses peuvent aussi altérer le comportement des CSM en sécrétant une autre chimiokine (CCL2; MCP-1) qui accroît alors le pouvoir invasif des CSM [10]. De plus, au niveau de l'os, un tissu majeur de colonisation et de développement de métastases dans le cas des cancers du sein et la prostate, les cellules tumorales peuvent stimuler la sécrétion par les CSM d'interleukine6 (IL-6), un facteur essentiel d'activa- tion des ostéoclastes (OC), et bloquer leur différenciation en ostéoblastes (OB) par l'expression du facteur de transcription Dkkl (dickkopf 1, un inhibiteur de Wnt) [11]. La résultante du déséquilibre de I'homéostasie $O B / O C$ favorise la dégradation des matrices osseuses.

À ce jour, il reste encore difficile de savoir si les CSM ont plutôt un rôle bénéfique ou néfaste sur l'évolution des cancers. II n'en reste pas moins que la capacité des CSM à migrer vers les sites tumoraux pourrait être utilisée dans des stratégies de thérapie cellulaire basées sur l'apport au sein de la tumeur de facteurs anti-angiogéniques et/ou sur l'ingénierie tissulaire pour réparer les tissus détruits, comme l'a montré notre équipe. Nous avons en effet montré que l'injection intra-tibiale de CSM génétiquement modifiées pour exprimer un facteur anti-angiogénique (fragment amino-terminal de l'activateur du plasminogène, ATF) réprime fortement la croissance intra-tibiale de cellules du cancer de la prostate chez la souris SCID (severe combined immunodeficient) et freine la lyse osseuse (données non publiées). $\diamond$

Multipotent stromal cells :

controversial impact on tumor

development and metastasis

\section{RÉFÉRENCES}

1. Paget $S$. The distribution of secondary growths in cancer of the breast. Lancet 1889; 1:571-3.

2. Combadière $B$, Combadière $C$, Deterre $P$. Les chimiokines: un réseau sophistiqué de guidage cellulaire. Med Sci (Paris) 2007 ; 23 : 173-9.

3. Friedenstein AJ, Chailakhyan RK, Gerasimov UV. Bone marrow osteogenic stem cells: in vitro cultivation and transplantation in diffusion chambers. Cell Tissue Kinet $1987 ; 20: 263-72$.

4. Dominici M, Le Blanc K, Mueller I, et al. Minimal criteria for defining multipotent mesenchymal stromal cells. The international society for cellular therapy position statement. Cytotherapy 2006; 8: 315-7.

5. Ali S, Lazennec G. Chemokines: novel targets for breast cancer metastasis. Cancer Metastasis Rev $2007 ; 26: 401-20$.

6. Studeny M, Marini FC, Champlin RE, et al. Bone marrow-derived mesenchymal stem cells as vehicles for interferon-beta delivery into tumors. Cancer Res $2002 ; 62: 3603-8$.

7. Djouad F, Plence P, Bony C, et al. Immunosuppressive effect of mesenchymal stem cells favors tumor growth in allogeneic animals. Blood 2003; 102 : 3837-44.

8. Karnoub AE, Dash AB, Vo AP, et al. Mesenchymal stem cells within tumour stroma promote breast cancer metastasis. Nature 2007 ; 449: 557-63.

9. Khakoo AY, Pati S, Anderson SA, et al. Human mesenchymal stem cells exert potent antitumorigenic effects in a model of Kaposi's sarcoma. J Exp Med $2006 ; 203: 1235-47$.

10. Dwyer RM, Potter-Beirne SM, Harrington KA, et al. Monocyte chemotactic protein-l secreted by primary breast tumors stimulates migration of mesenchymal stem cells. Clin Cancer Res 2007 ; 13 : 5020-7.

11. Gunn WG, Conley A, Deininger L, et al. A crosstalk between myeloma cells and marrow stromal cells stimulates production of DKKl and interleukin-6: a potential role in the development of lytic bone disease and tumor progression in multiple myeloma. Stem Cells 2006 ; 24 : 986-91.

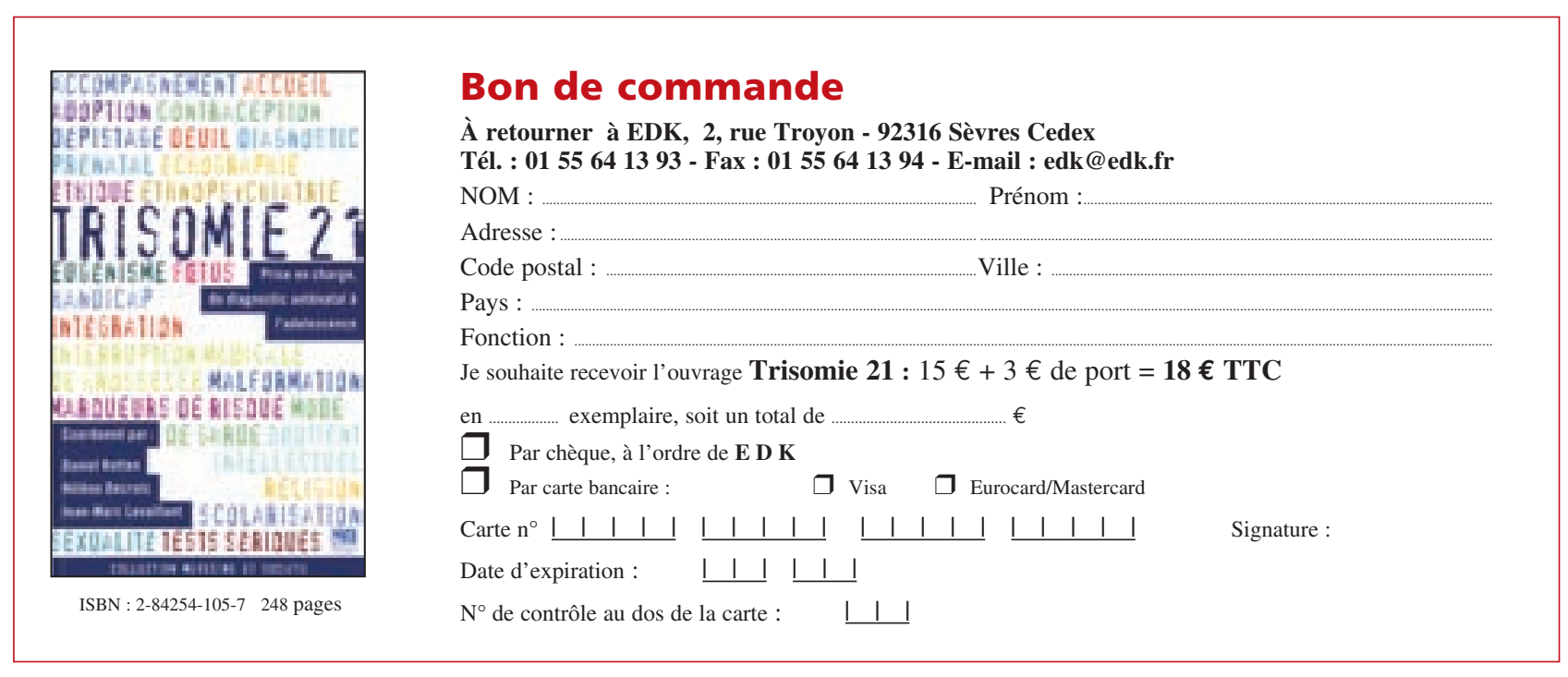

